\title{
Articulando a Transformative Consumer Research e a Comunicação Não-Violenta em Situações de Insegurança Alimentar em Grupos Vulneráveis
}

\section{Articulating Transformative Consumer Research and Non-Violent Communication in Food Insecurity in Vulnerable Groups}

\author{
Gustavo Tomaz de Almeida ${ }^{1}$, Georgiana Luna Batinga² ${ }^{2}$ Bruno Medeiros Assimos ${ }^{2}$, Marcelo de Rezende \\ Pinto $^{2}$ \\ ${ }^{1}$ Universidade do Estado de Minas Gerais, UEMG, Brasil, ${ }^{2}$ Pontifícia Universidade Católica de Minas Gerais, \\ PUC-MG, Brasil. \\ Correspondência: Gustavo Tomaz de Almeida. Rua Major Lopes, 574, São Pedro CEP 30.330-050, Belo \\ Horizonte, MG, Brasil. Telefone: +55 (31) 3194-2519. E-mail: gustavo.almeida@uemg.br.
}

Recebido: 08 de janeiro de 2018 Aceito: 28 de setembro de 2018 Publicado: 28 de dezembro de 2018

DOI: http://dx.doi.org/10.21714/1679-18272018v16n2.p154-166

\begin{abstract}
Resumo
A Transformative Consumer Research - TCR é um movimento ou abordagem de pesquisa que visa melhorar o bem-estar de consumidores vulneráveis. O objetivo nesse artigo é adicionar na agenda das pesquisas transformativas uma Tecnologia Social intitulada Comunicação Não-Violenta - CNV, visto que não existem artigos nacionais e internacionais que tenham proposto essa articulação. Em termos teóricos, elegemos um público vulnerável, quer seja, os consumidores em situação de insegurança alimentar, para articular os conceitos de Tecnologia Convencional e Social, CNV e TCR. Metodologicamente, se desenvolveu uma revisão de literatura do tipo narrativa, de trabalhos nacionais e internacionais, tendo como produto um ensaio teórico. Como principais resultados e conclusões, o que se ganha ao aliar a CNV com a TCR é que o consumidor participante da pesquisa, ao adquirir a consciência de si e do outro, disponha a transformar-se, direcionando seu próprio pensamento às suas necessidades não atendidas, sendo o papel do pesquisador, ser apenas um mediador para ajudar o outro a encarar as transformações relacionadas a insegurança alimentar.
\end{abstract}

Palavras-chave: TCR, Insegurança alimentar, Tecnologia social, Comunicação não-violenta.

\begin{abstract}
Transformative Consumer Research - TCR is a movement or research approach aimed at improving the well-being of vulnerable consumers. The purpose of this article is to add a Social Technology called Non-Violent Communication (CNV) in the transformational research agenda, since there are no national and international articles that have proposed this articulation. In theoretical terms, we elected a vulnerable public, whether consumers in situations of food insecurity, to articulate the concepts of Conventional and Social Technology, CNV and TCR. Methodologically, a literature review of the narrative type of national and international works was developed, having as product a theoretical essay. As the main results and conclusions, what is gained by allying the CNV with the TCR is that the consumer participating in the research, when acquiring the consciousness of self and the other, is willing to transform, directing their own thinking to their unmet needs, being the role of the researcher, to be only a mediator to help the other to face the transformations related to food insecurity.
\end{abstract}

Keywords: TCR, Food insecurity, Social technology, Non-violent communication.

Esta obra está licenciada sob uma Licença Creative Commons Attribution 3.0

\section{Introdução}

A TCR elegeu o bem-estar do consumidor como seu tema direcionador e dominante, assumindo a importância do equilíbrio entre as necessidades físicas, psicológicas, econômicas e sociais nos ambientes de consumo, ao mesmo tempo em que contribui para a igualdade, justiça social, distribuição de recursos e oportunidades. Essa visão é um 
dos seus compromissos, mantendo o rigor que possa robustecer o desenvolvimento e aprimoramento da visão transformativa (MICK et al., 2012). Contudo, do ponto de vista metodológico, ainda existe uma questão entre os acadêmicos de como atingir essa transformação sem impor ao participante da pesquisa uma realidade baseada no julgamento moral do pesquisador, daquilo que é certo ou errado?

É a partir dessa indagação que parece fazer sentido trazer para a discussão a proposta de Tecnologias Sociais - TS. Contudo, antes de apresentarmos o conceito de TS, vale esclarecer o que consideramos ser "Tecnologia", uma vez que não existe um conceito único a respeito dessa palavra. Nesse artigo, o termo "Tecnologias" deve ser compreendido de forma ampla, como o resultado da aplicação de conhecimentos para a solução de problemas práticos, buscando o bem-estar de todos. Optamos por esse conceito, pois ele permite compreender as TS como inclusivas, emancipatórias e distributivas (DAGNINO, 2009). Por sua vez, as Tecnologias Sociais, na visão de Lassance Júnior (2004), podem ser consideradas como um conjunto de técnicas e metodologias transformadoras, desenvolvidas e/ou aplicadas na interação com a população e apropriadas por ela, que representam soluções para inclusão social e melhoria das condições de vida. Complementarmente, Rodrigues e Barbieri (2008) defendem o potencial inovador dessas tecnologias para a solução de problemas que afetam a maioria dos seres humanos, como os relacionados com a demanda por água, alimentos, educação, energia, saúde, entre outros, ao mesmo tempo que promovem a inclusão social e protegem o meio ambiente.

Diante dessas reflexões, surge a motivação de se promover uma discussão com o intuito de verificar quais são os pontos de aderência entre a TCR e as Tecnologias Sociais e as possíveis formas de articulação entre as duas propostas. Tendo em vista a amplitude do conceito de Tecnologias Sociais, a opção foi focar a discussão em uma TS denominada Comunicação Não-Violenta - CNV. A escolha advém justamente da ideia da CNV em respeitar a emancipação do participante por meio da obtenção da consciência de si e do outro, neste caso, pesquisado e pesquisador.

Dessa forma, parece emergir a questão que guiou a estruturação e a condução desse ensaio: Como a Tecnologia Social denominada Comunicação Não-Violenta pode contribuir para o desenvolvimento e fortalecimento da TCR? Cabe esclarecer que, no contexto desse trabalho, os termos Comunicação e Discurso são tratados como sinônimos, embora haja diferenças teóricas entre eles.

Há, contudo, um outro ponto essencial a ser destacado no trabalho. Para focar a discussão em um contexto específico, optou-se pela temática de grande apelo social e político na atualidade que é o do combate à insegurança alimentar. Conforme destacado por Buainain, Garcia e Vieira (2016), a situação de insegurança alimentar referese à limitação ou mesmo à incerteza em relação à disponibilidade nutricional adequada para as pessoas. Esse conceito veio, ao longo das últimas décadas, ganhando contornos distintos que acabam por torna-lo essencial quando se discutem temáticas como vulnerabilidade social, economia solidária, gestão ambiental, políticas públicas, entre outras.

Dentre as demais justificativas que nos fazem acreditar no potencial deste trabalho, observamos a aderência da CNV à TCR, uma vez que ambas se preocupam em atender as necessidades de indivíduos em situações de vulnerabilidade. A CNV, contudo, traz contribuições complementares, que serão mais discutidos no desenvolvimento, quer sejam: a) a interação compassiva e seu poder para contribuir com o bem-estar do indivíduo; b) a comunicação violenta, enquanto cultura legitimada de dominação do discurso que justifica o uso da violência e reduz o potencial transformativo; c) contribui para a delimitação do conceito de transformação, reduzindo as críticas que lhe são caras, pois tanto a CNV quanto a TCR não objetivam educar a pessoa para transformá-la, antes, se comprometem a despertá-la a fim de que ela transforme-se.

Ainda como justificativas para o ensaio, no tocante ao objeto de estudo que é o da insegurança alimentar, não encontramos trabalhos que discutem TCR e CNV nesse contexto. É possível citar apenas uma pesquisa publicada no ano de 2017 na qual o autor reconhece as relações entre bem-estar dos consumidores para melhorar comportamentos alimentares por meio de uma rotulagem nutricional e a TCR (NABEC, 2017). Por fim, esse ensaio pode ser útil para pesquisas futuras, uma vez que lança luz sobre possibilidades de propostas de programas sociais que tenham como objetivo reduzir a insegurança alimentar por meio da TCR.

\section{O Debate Em Torno Da Insegurança Alimentar}

Inicialmente, cabe alertar que a discussão sobre o desafio alimentar no século XXI não é algo simples e vai muito além das questões relacionadas ao aumento da população e à produção de alimentos. Diferentemente do que se acreditava até a década de 1970, quando a produção insuficiente de alimentos era o determinante da fome no mundo e, posteriormente, na década de 1980, quando se achava que o problema estava atrelado à iniquidade na distribuição de alimentos, nas últimas décadas, outras noções foram incorporadas. Entre elas, podem ser citadas a noção de qualidade da dieta, o respeito aos hábitos alimentares dos diferentes grupos culturais, o conceito de alimento seguro, a incorporação dos conceitos de eqüidade e sustentabilidade ambiental, além da articulação com 
o provimento de outras necessidades básicas, como saúde, educação e moradia, para alcançar a plenitude da segurança alimentar (PEREIRA; SANTOS, 2008). Ou seja, o debate da insegurança alimentar passou a se relacionar com um conjunto de novos condicionantes, tais como o papel da dimensão ambiental, aspectos da demanda mundial e a nova dieta alimentar da população, questões do mercado de alimentos, entre outras (BUAINAIN; GARCIA; VIEIRA, 2016).

Quanto às políticas públicas de segurança alimentar no Brasil, é possível salientar, tal como defendido por Almeida et al (2006), que a partir dos primeiros anos do século XXI, esse conceito mais amplo de segurança alimentar passou a subsidiar as ações governamentais no sentido de não somente reduzir a fome da população miserável, mas também passou a incentivar ações solidárias para pessoas em situação de vulnerabilidade no país (incluindo pessoas produtivas, como trabalhadores rurais, agricultores familiares, entre outros).

Deve-se destacar ainda o esforço de pesquisadores no sentido de desenvolver escalas para a mensuração de segurança alimentar. Nesse sentido, vale citar a pesquisa de Correa (2007) que tomando o instrumento de medida de segurança alimentar desenvolvida na Universidade de Cornell, promoveu uma adaptação para o contexto brasileiro, surgindo, assim, a Escala Brasileira de Insegurança Alimentar (EBIA).

A despeito da importância desses esforços em desenvolver escalas de mensuração do fenômeno da insegurança alimentar que pode servir de balizamento para os gestores públicos, sobram espaço para a utilização de métodos e técnicas que, por meio de projetos sociais, possam promover de alguma forma a sensibilização e até mesmo a transformação dos indivíduos em situações de vulnerabilidade em termos de insegurança alimentar. É justamente nesse contexto que parecem fazer sentido a articulação das propostas da TCR e das tecnologias que serão discutidas nos próximos tópicos.

\section{O termo Tecnologia}

De início, vale esclarecer que diversos conceitos são atribuídos ao termo Tecnologia, ao longo da história. Nesta discussão, Feenberg (2005) organiza as diversas construções conceituais em dois eixos e quatro visões, segundo as quais se podem examinar as relações entre tecnologia e sociedade: a) Horizontalmente, uma tecnologia por ser controlada pelo ser humano ou autônoma deste controle; b) Verticalmente, uma tecnologia pode ser carregada de valores, que formam um estilo de vida ou totalmente neutras, o que equivale a separação completa entre meios e fins; c) Da combinação dos eixos horizontal e vertical, surgem quatro visões distintas, ou seja, uma tecnologia pode ser encarada via Instrumentalismo, Determinismo, Teoria Crítica ou Substantivismo (QUADRO 1).

Quadro 1: Concepções do conceito de tecnologia.

\begin{tabular}{|c|c|c|}
\hline \hline A tecnologia é: & Autônoma & Humanamente controlada \\
\hline $\begin{array}{c}\text { Neutra (separação } \\
\text { completa entre } \\
\text { meios e fins) }\end{array}$ & $\begin{array}{c}\text { Determinismo } \\
\text { (Por exemplo: a teoria da modernização) }\end{array}$ & $\begin{array}{c}\text { Instrumentalismo } \\
\text { (Fé liberal no progresso) }\end{array}$ \\
\hline $\begin{array}{c}\text { Carregada de } \\
\text { Valores (meios } \\
\text { formam um modo } \\
\text { de vida que inclui } \\
\text { fins) }\end{array}$ & Substantivo & $\begin{array}{c}\text { Teoria Crítica } \\
\text { (Escolha de sistemas de meios- } \\
\text { fins alternativos) }\end{array}$ \\
\hline \hline
\end{tabular}

Fonte: Feenberg (2005, p.6).

Em complemento, para Feenberg $(2004,2005,2009)$, uma tecnologia é autônoma quando sua descoberta e desenvolvimento têm leis imanentes próprias, as quais os humanos simplesmente seguem ou interagem neste domínio técnico. Por outro lado, se ela é humanamente controlada, é possível determinar o próximo passo de evolução, de acordo com as intenções humanas.

Passando a abordar as quatro visões oriundas das combinações, a primeira, denominada Instrumentalismo, oferece a visão mais amplamente aceita no senso comum de que as tecnologias são ferramentas prontas para servir as necessidades dos usuários, sendo neutra (sem conteúdo valorativo próprio) e de possível controle humano. A teoria instrumentalista da tecnologia, tanto na forma marxista quanto não marxista, pressupõe que os sujeitos de ação por exemplo, o consumidor - controlam os meios. Entretanto, uma crítica feita por Feenberg $(2004,2005,2009)$ 
é que a realidade e os meios, incluindo a tecnologia, são dialeticamente interligados. Como exemplo disto, a escola não explora os conhecimentos dos professores como meios para atingir seus fins educacionais, mas se constitui enquanto ator por mediação destes meios. Por esse motivo, em contraposição ao Instrumentalismo, surge a Teoria Crítica da Tecnologia, da qual centra nosso interesse e será descrita mais adiante.

Já no Determinismo, embora a neutralidade seja aceita, é combinada com a autonomia. Isso indica que a tecnologia não é controlada pelo homem, sendo ela que molda a sociedade, em termos de exigências de eficiência e progresso (FEENBERG, 2004, 2005, 2009). Nesta abordagem, a tecnologia emprega o desenvolvimento do conhecimento do mundo natural para servir às características universais de natureza humana. Como exemplos, o carro é uma extensão dos nossos pés, enquanto os computadores estendem nossa inteligência. Cabe ao homem adaptar-se à tecnologia como expressão mais significativa da humanidade.

$\mathrm{Na}$ terceira abordagem, a visão denominada Substantivismo, se atribuem valores substantivos à tecnologia, demonstrando um compromisso com uma concepção específica de uma vida boa. No entanto, a autonomia preservada pelo Substantivismo caracteriza um perigo, já que "a tecnologia uma vez libertada fica cada vez mais imperialista, tomando domínios sucessivos da vida social" (FEENBERG, 2005, p.8). Nesta perspectiva, o sistema tecnológico promove uma instrumentalização total de indivíduos e se apresenta como necessidade e destino. Logo, se a tecnologia é o veículo de uma cultura de dominação, a sociedade está condenada a seguir seus avanços em direção à distopia, isto é, "um mundo no qual a individualidade humana foi completamente suprimida" (FEENBERG, 2005, p. 8).

Na última visão, a Teoria Crítica da Tecnologia, os valores incorporados na tecnologia são socialmente específicos, não sendo representados por abstrações como eficiência ou controle. Essa afirmação, contraria o Substantivismo, no qual os valores presentes na tecnologia são exclusivos dela e incluem metas de produtividade e poder. Na Teoria Crítica, uma tecnologia não molda só um modo de vida, mas muitos estilos diferentes de vida. E, igualmente ao instrumentalismo, considera que a tecnologia pode ser controlada pelo ser humano, contudo, não como ferramentas, mas como meio para alcançar estilos de vida (FEENBERG, 2004, 2005, 2009). E, por este motivo, esse estudo se adere ao conceito de Tecnologia na visão da Teoria Crítica. Em outras palavras, essa opção ocorre, pois, nesta visão as escolhas estão abertas para as pessoas e é possível a humanidade escolher o mundo no qual deseja viver.

\begin{abstract}
A teoria crítica da tecnologia sustenta que os seres humanos não precisam esperar um Deus para mudar a sociedade tecnológica num lugar melhor para viver. A teoria crítica reconhece as consequências catastróficas do desenvolvimento tecnológico ressaltadas pelo Substantivismo, mas ainda vê uma promessa de maior liberdade na tecnologia. O problema não está na tecnologia como tal, senão em nosso fracasso até agora em inventar instituições apropriadas para exercer o controle humano dela (FEENBERG, 2005, p.9).
\end{abstract}

Deste modo, neste trabalho, o termo "Tecnologias" deve ser compreendido de forma ampla, como o resultado da aplicação de conhecimentos para a solução de problemas práticos, buscando o bem-estar de todos. Esse conceito permite compreender as TS como inclusivas, emancipatórias e distributivas (DAGNINO, 2009). Ganha espaço, portanto, as tecnologias sociais que serão discutidas no próximo tópico.

\title{
4. As Tecnologias Sociais (TS)
}

As relações políticas e sociais em sociedades capitalistas são marcadas por Tecnologias Convencionais - TC que reflitam a redução dos custos de mão de obra (por exemplo, pela busca de Tecnologias que substituíam o trabalho manual pelo mecânico), maximização dos resultados, acúmulo de capital dos acionistas, ao mesmo tempo em que contribuem para o desemprego e a exploração do trabalhador (ABRAMIDES, CABRAL, 2003). Em contraposição a essa lógica, surge a Tecnologia Social - TS, com origens no final do século XIX, quando Gandhi iniciou o processo político revolucionário em busca da independência da Índia, a partir de três princípios: a autossuficiência; a crítica ao consumo "desnecessário" e a ausência do medo (BARBIERI, 1989; HERRERA, 2010). Porém, nesta época o nome dado era Tecnologia Apropriada (TA), equivalente ao trabalho em que Gandhi aplicou e disseminou um processo de fiação desenvolvido em uma roça, que primava a ampliação do trabalho humano e permitisse o sustento das populações, reduzindo a importância do sistema industrial na economia local (HERRERA, 2010; BARRETTO, PIAZZALUNGA, 2012).

Por sua vez, as ações da TA levaram a criação das Tecnologias Intermediárias (TI) por Schumacher (1973), buscando equalizar o desenvolvimento econômico, social e ambiental de países subdesenvolvidos por meio de tecnologias com baixo custo, fácil uso e que permitissem a produção em pequena escala e primasse o meio ambiente. O conceito foi introduzido pelo autor num relatório elaborado em 1963 para a Indian Planning Comission e depois apresentado em 1964, à Cambridge Conference on Rural Industrialization. A TI teve início em 1966, quando um grupo de profissionais e industriais do Reino Unido fundaram uma companhia limitada sem fins lucrativos, preocupados com os perigos decorrentes do aumento do desemprego que ocorria em quase todos 
os países pobres. Diferente das demais abordagens, eles não queriam dar a eles o que lhes faltava, mas desenvolver meios para vencerem a pobreza com seus próprios esforços (SCHUMACHER, 1973).

Os conceitos relacionados às TA e TI disseminaram rapidamente, pautados em ações possíveis de inclusão social e participação das nações periféricas no mercado internacional. Apesar disto, os elementos estruturais do sistema econômico ainda eram mantidos na prática (DAGNINO, 2009). Por isso, na tentativa de evoluir conceitualmente em relação as TA e TI, visando o surgimento de uma outra lógica econômica, surgem as Tecnologias Sociais. A mudança conceitual em relação as duas abordagens anteriores, está no fato de que a transformação se daria através do fortalecimento da economia solidária - ES, com formas mais colaborativas da relação do trabalho e sustento da sociedade. Desde sua origem, o desenvolvimento de uma TS segue com as seguintes premissas: deve fomentar a sustentabilidade social, econômica e ambiental; fortalecer a ES como opção diante da economia capitalista e, por último, articularem-se com o contexto do desenvolvimento da Tecnologia e Ciência (DAGNINO, 2009).

Ainda em termos conceituais, embora não haja um consenso na academia, uma das abordagens mais utilizadas é que a TS compreende o resultado da ação coletiva dos produtos sobre um processo de trabalho, em função de um contexto socioeconômico e um acordo social que permitam criar um controle (autogestão) ao mesmo tempo em que gera uma cooperação voluntária e participativa, que modifica o produto gerado a ponto de ser apropriado segundo a decisão do coletivo (DAGNINO, 2009).

No Brasil, o uso das TS teve início no ano de 2000 (DAGNINO, 2009) e, desde então, pesquisadores tem se dedicado a difundir seus conceitos e práticas, em especial os vinculados a UnB e Unicamp. O Quadro 2 busca sumarizar alguns dos trabalhos que tiveram como proposta a difusão dos conceitos, pressupostos, metodologias e técnicas das TS no Brasil.

Quadro 2: Trabalhos que buscam difundir a TS no Brasil.

\begin{tabular}{|c|l|}
\hline \hline Obras: & \multicolumn{1}{c|}{ Principais contribuições: } \\
\hline $\begin{array}{c}\text { Lassance Júnior } \text { et } \\
\text { al. (2004) }\end{array}$ & $\begin{array}{l}\text { Considerado um trabalho marco à conceituação e análise da aplicação da TS no } \\
\text { país, por meio de textos de seis articulistas de diferentes setores que defendem a } \\
\text { Rede de Tecnologia Social - RTS, trazendo debates teóricos e relatos empíricos. }\end{array}$ \\
\hline Dagnino (2008) & $\begin{array}{l}\text { Discute a possibilidade de se construir um estilo de desenvolvimento socialmente } \\
\text { justo e economicamente viável sobre estruturas diferentes das concebidas pela } \\
\text { visão tecnológico-científica. Baseia-se em valores e interesses prevalecentes da } \\
\text { sociedade que se planeja transformar. }\end{array}$ \\
\hline Dagnino (2009) & $\begin{array}{l}\text { Reúne obras de estudiosos latino-americanos dos Estudos Sociais da Ciência e } \\
\text { Tecnologia, preocupados com a relação entre desenvolvimento social e tecnologia, } \\
\text { focando os vários agentes, sejam eles acadêmicos, políticos, representantes de } \\
\text { movimentos sociais e outros. Além disso, o autor traz abordagens analítico- } \\
\text { conceituais da TS, seus arranjos institucionais e as dificuldades enfrentadas para } \\
\text { sua disseminação. }\end{array}$ \\
\hline Otterloo et al. & $\begin{array}{l}\text { Trazem uma discussão profunda dos membros integrantes da RTS, refletindo sobre } \\
\text { o papel das TS para o desenvolvimento do Brasil, pensando nas individualidades e } \\
\text { potencialidades de cada região, bem como em relação aos modos como distintos } \\
\text { atores podem se articular por meio de TS, sugerindo a criação de uma plataforma } \\
\text { compartilhada de ações. }\end{array}$ \\
\hline Neder (2009) & $\begin{array}{l}\text { Analisa como o marco regulatório de Ciência, Tecnologia e Inovação influenciam } \\
\text { as inovações, as TS e as políticas públicas relacionadas. O autor analisa ainda as } \\
\text { condições para que os recursos destinados às políticas de inovação empresarial } \\
\text { possam ser direcionados igualitariamente para ambientes de políticas públicas de } \\
\text { desenvolvimento e inclusão social, através de uma regulamentação adequada da } \\
\text { política de Ciência, Tecnologia e Inovação. }\end{array}$ \\
\hline \hline
\end{tabular}

Fonte: Elaboração própria.

Contudo, o desenvolvimento da TS no Brasil ainda é um movimento bastante embrionário, visto que a TS pouco se desenvolveu inclusive no mundo e avançaram timidamente em formas de associativismo ou cooperação (DAGNINO, 2010), urgindo a necessidade de alianças que aprofundem esta discussão e reduzam os impasses para sua disseminação. É neste intuito que se discute no próximo trecho a Comunicação não-violenta - CNV para, mais adiante, harmonizá-la com a TCR. 


\section{A Tecnologia Social: Comunicação Não-Violenta - CNV}

Antes de explicar a CNV, é preciso contextualizar o que seria uma Comunicação Violenta - CV, para essa TS. Neste sentido, para Rosenberg (2006) a CV é uma expressão de uma necessidade não atendida, sendo o discurso (o meio pelo qual as pessoas se conectam) à expressão explícita da violência. Esse discurso violento está legitimado historicamente, datado há mais de oito mil anos, quando o homem desenvolveu o pensamento selvagem de matar para sobreviver. Em momentos históricos posteriores, a violência se vê presente na comunicação como demonstração de poder e supremacia: agora, os homens lutam em nome de Deus e a morte dos membros de uma cultura religiosa é aceita, justa e esperada por representantes da cultura oposta. Outro exemplo está no poder dos reis, em que as deliberações em nome da coroa foram legitimadas ao longo de séculos, independente dos malefícios que possam ocasionar aos súditos ou a outra monarquia. A própria estrutura da linguagem, se vista no espectro da Antropologia, também remete a cultura de dominação, quando categoriza os grupos em peões e realeza. Em todos esses exemplos a punição é aceita como um discurso que reifica a violência (ROSENBERG, 2006).

Nos dias mais recentes, o discurso político também reforça esta prática. A comunicação é que a política vai promover a transformação do bem-estar das pessoas, com o pressuposto que as necessidades de todos estão em perigo e precisam ser protegidas. Mas será que a política de fato atende as necessidades de todos? Será que não é feito um jogo de razão para definir "quem é o quê" "quem está no comando" e "quem está certo"? Rosenberg (2006) complementa que não é preciso ir muito longe para pensar no quanto a sociedade legitima a violência: desde a infância a criança apreende uma cultura de que o herói tem o direito a matar o bandido e a morte é um caminho benquisto. Segundo o autor, o resultado desta cultura reflete, durante toda a vida, em julgamentos morais se esse fato atende ou não as necessidades de quem julga, e não a transformação de quem é julgado. Deste jogo, surge ou a recompensa ou a punição, tornando a competição como algo naturalizado e inerente ao indivíduo. Nessa lógica, a sociedade vive numa "agradável" (no sentido de aceita) cultura de violência, desumanizando o outro e negando seu direito, na visão de Rosenberg (2006).

Em contraposição a esse cenário, a CNV é uma abordagem que visa desenvolver no sujeito a consciência desta cultura violenta. Afinal, se todos a tivessem, não faltariam nem comida ou medicamento, dado que ambos podem ser abundantes se não houvesse a disputa de território (ROSENBERG, 2006). A origem da CNV está na Psicologia e o termo foi cunhado por Marshall Rosenberg em 1976, inspirado nos contatos que ele teve no seu doutorado com a psicologia clínica e os avanços dos estudos do seu orientador, que se opunha a ideia de que tudo seria melhor explicado por fatores patológicos. Seu conceito foi disseminado no campo profissional e acadêmico, incluindo na agenda palestras realizadas por todo o mundo pelo próprio fundador do conceito. No Brasil, sua obra foi traduzida no ano de 2006 e, embora Rosenberg tenha falecido em fevereiro de 2015, na atualidade existem mais de cem certificadores da temática filiados a sua Associação, dando continuidade aos trabalhos (CNVC, 2015).

O objetivo central desta TS é buscar prover o indivíduo de condições para gerenciar suas decisões, resolvendo conflitos e promovendo o bem-estar a partir da necessidade de todos, por meio da interação compassiva (ROSENBERG, 2006). Nesse sentido, foca o poder que a sociedade tem para contribuir com o bem-estar das pessoas, entendendo que este dar natural (a interação compassiva) possui mais valor que a recompensa cultural da troca de bens materiais. O cerne da CNV está na busca do sujeito pela transformação via empatia e não por simpatia, equivalente a transformação do sujeito ao adquirir a consciência de si e do outro, agindo com base em um ato de própria vontade: sem ser coagido por um terceiro, mas por uma vontade que vem, segundo Rosenberg (2006) nomeia, da sua própria decisão.

Para ficar mais nítida a diferença entre $\mathrm{CV}$ e CNV, um exemplo pode ser dado e em ambos existem a transformação - a princípio, contudo em um ocorre via simpatia e noutro por meio da empatia. Imagine a seguinte situação: numa visão CV a depressão pode ser encarada como uma doença mental, essas pessoas possuem um duplo sofrimento uma vez que julgam por se julgarem e permanecem engessadas nas estruturas reificadas do pensamento. $\mathrm{O}$ resultado deste processo é a pessoa se atacar ou envergonhar-se. E o papel de um terceiro, nesta visão CV, é transformar essa pessoa. O movimento da transformação, portanto, parte do pesquisador para o pesquisado, com base no julgamento moral do primeiro do que seria o melhor para o pesquisado, ou seja, com base na simpatia, colocando o outro a satisfazer o seu dispor, isto é, que ele perceba o que quero e assim faça (ROSENBERG, 2006).

Já em uma visão $\mathrm{CNV}$, a depressão pode ser encarada mais como um distúrbio químico e físico resultante da violência do planeta. Assim, o que reforça o conflito é a linguagem que a pessoa conta a si mesmo. A CNV atua, neste processo, questionando esses julgamentos, para entender quais as necessidades não são atendidas. A visão transformativa neste caso é que o próprio participante se transforme, isto é, transforme o pensamento sobre ele mesmo por meio da empatia: tenha consciência de si e do outro no contexto, por um ato de própria vontade, perceba quais necessidades não estão sendo atendidas para todos e transforme-se. O movimento, portanto, inicia e está mais presente na consciência e vontade própria do pesquisado (ROSENBERG, 2006). 
Em termos práticos esse estágio é alcançado quando um terceiro (o pesquisador, por exemplo) questiona o participante (que pode ser o consumidor) sobre: Quais as necessidades não são atendidas? Esta é a única pergunta. Nesta fase, surge o primeiro empasse, pois, a mente humana está histórica, cultural e socialmente programada para diagnosticar patologias e categorizar as coisas (por exemplo, assassinos versus dominados). Desta etapa, os aparatos das construções sociais reificadas são trazidos à tona pelo participante, para legitimar sua resposta, referindo-se a lei (a constituição federal, por exemplo) para justificar suas posições por meio de julgamentos intelectuais. Contudo, a pergunta feita pelo pesquisador não tem relação com essa resposta. A questão era bem simples: Quais as necessidades não estão sendo atendidas? (ROSENBERG, 2006).

Neste ínterim, o autor descreve ser difícil encarar suas necessidades quando se vê o outro como inimigo. Por isso, via discurso, o pesquisador deve ter uma sensibilidade suficiente para compreender o que está por trás destes julgamentos morais (podendo, por exemplo, refletir uma necessidade de segurança não atendida) e trazer isso para discussão entre os participantes daquela comunicação. Se a análise do pesquisador estiver incorreta a pessoa ou o grupo, conforme o caso, pode corrigir. Embora isso, a maior dificuldade deste processo é conseguir que a pessoa se conecte, isto é, que ela te ouça e seja ouvida. Mas, depois de várias rodadas de conversa, em que se foque as necessidades que não estão sendo atendidas, o pesquisador consegue atingir um estágio em que o outro encare suas necessidades e resolva os conflitos via interação compassiva, e não por luta, disputa ou julgamentos morais (ROSENBERG, 2006). Essas rodadas demandarão tempo, paciência e longas viagens do pesquisador, de acordo com o contexto; por isso se ele dispor a transformar o campo via CNV, deverá ter essa disponibilidade, também como princípio, para desenvolver estudos longitudinais de anos ou décadas, até conseguir que a pessoa ou grupo foque em suas necessidades.

Nesta tarefa, ainda do ponto de vista metodológico, ao adquirir consciência, o participante também percebe a responsabilidade que ele possui no "contexto do contexto". Mas é difícil chegar a este estágio pelas limitações humanas, isto é, sem perder a autoestima. O trabalho do pesquisador, segundo Rosenberg (2006) entende, é contribuir para que o sujeito encare a verdade e perceba que suas ações resultam de sua vontade, o que não significa que suas opções e escolhas sejam boas. No âmbito da gestão, a ausência dessa responsabilização é vista pelo que o autor chama de Linguagem Amtsprache, que na tradução livre do alemão, representa uma linguagem do burocrata. Em nome desta linguagem, ações são praticadas como se a pessoa não tivesse opção ou responsabilidade, pois só está seguindo ordens superiores e as políticas organizacionais.

É, portanto, um papel difícil para o pesquisador, mas Rosenberg (2006) e seus seguidores acreditam que a transformação é mais possível deste modo. Afinal, querer ensinar o sujeito para mudá-lo pode criar resistência, pois reflete seu sentimento impondo algo ao outro, de forma violenta, visto ser baseada no seu julgamento. É preciso que a pessoa se transforme por um ato de vontade própria, e não por coerção. É preciso, para que a transformação ocorra, que o participante da pesquisa se livre da imagem dos julgamentos e diagnósticos para justificar suas posições e comportamentos, passando a observar os fatos sem avaliar moralmente, sendo esta a mais elevada forma de inteligência humana para Rosenberg (2006).

Embora todas as dificuldades descritas, o pesquisador que se aprofunda na CNV consegue perceber a comunicação que bloqueia a transformação. De acordo com Rosenberg (2006) não é possível chegar a essa visão transformativa, sem que antes o pesquisador tenha uma sensibilidade em perceber a violência presente no discurso. Por exemplo, quando o participante relata ao pesquisador que diante de uma dada situação ele se sente intimado, incompreendido, usado, manipulado, julgado, criticado, ignorado, rejeitado, traído, ou ainda que o outro "faz-me sentir" ou "sinto-me assim porquê você", isso reflete uma interpretação suicida. A esse fato, o autor nomeia de Cultura Chacal, em que os sentimentos são prestativos o bastante para colocar a culpa como forma de manipular as pessoas, ou seja, de querer que ela se transforme por coerção ou simpatia. Em uma cultura violenta, a manipulação antecede a culpa, que pode levar ao convencimento e em um movimento em que a transformação ocorre partindo do pesquisador ao pesquisado ou simplesmente não ocorre. O que, para Rosenberg (2006), é algo suicida já que, como dito, ensinar para mudar pode criar resistência e uma transformação que não se sustente, pois não inicia no pesquisado.

Em uma tentativa de sumarização, em uma estrutura em que o pesquisador eleja a CNV para trabalhar, parte-se do pressuposto de que, independente da estrutura, o participante possui agência suficiente (ainda que os valores estejam esquecidos no inconsciente), há liberdade e responsabilidade por suas escolhas e, por isso, a pessoa não permite que as instituições determinem o que deve ou não fazer, desenvolvendo esse pensamento via empatia.

\section{O Movimento da Transformative Consumer Research}

A TCR é um movimento desenvolvido desde o ano de 2005, por pesquisadores do campo do comportamento do consumidor pertencentes à Association for Consumer Research - ACR (MICK et al., 2012; CROCKETT et al., 
2013). Estuda as experiências de consumo por grupos de consumidores vulneráveis, tais como pessoas com dificuldades de acesso a uma alimentação adequada (ACR, 2015; DAVIS e PECHMANN, 2013). Ela nasce do descontentamento com o modo pelo qual o positivismo aborda temas relacionados a sujeitos socialmente desfavorecidos e/ou excluídos (MERTENS, 2007, 2007a; DAVIS; OZANNE e HILL, 2016). Neste contexto, o passo inicial para tentar amenizar os problemas de alimentação no planeta é compreender que essas pessoas possuem necessidades diferentes e, por esse fato, podem enfrentar limitações distintas.

Dentre as justificativas de se trabalhar nesta perspectiva, Coelho (2015) e Heath e Chatzidakis (2012) citam a possibilidade de o pesquisador assumir uma postura distinta do marketing convencional, preocupando-se mais com a transformação do que outras "lógicas" do campo acadêmico, haja vista as seguintes questões: a) a pressão do campo por publicações; b) a falta de diálogo entre os grupos de pesquisa; c) o distanciamento entre academia e a sociedade; d) o maior foco gerencial na produção científica; e) a linguagem acadêmica incompreensível, por vezes, para àqueles que estão fora. Além disto, a abordagem transformativa em marketing é escassa, quando comparada à medicina, enfermagem, terapia ocupacional e outras. A intenção, portanto, é promover a justiça social nos ambientes de consumo, a partir de um equilíbrio das necessidades físicas, psicológicas, econômicas e sociais (COELHO, 2015; MARI, 2011).

Seu precursor, David Mick, aliado a Simone Pettigrew, Cornelia Pechmann e Julie Ozanne descrevem a TCR como um movimento de pesquisas que primem à qualidade de vida dos atingidos por demandas, potencialidades e efeitos do consumo, com certa visão emancipatória, no sentido de promover mudanças no indivíduo ou grupo objeto do estudo (MICK et al., 2012; OZANNE et al., 2011; PARKER, 2014).

Para os autores, os compromissos da TCR envolvem: a) promoção do bem-estar, concentrando-se nos problemas e oportunidades sociais; b) promoção da diversidade de paradigmas, teorias e métodos que sejam capazes de retratar os problemas encontrados a campo; c) emprego de teorias e métodos rigorosos: utilizando metodologias distintas de acordo com o objetivo de cada estudo; d) descrição de contextos socioculturais e situacionais, ilustrando os anseios das pessoas inseridas em uma conjuntura, na qual a Antropologia e Sociologia contribuem para o debate; e) formação de parcerias com consumidores, a partir da aproximação com instituições que serão beneficiadas pelos resultados da pesquisa e; f) divulgação dos resultados não apenas ao campo acadêmico, mas também às instituições e participantes envolvidos com a pesquisa. Nota-se, com isso, que o uso da TCR se inova na academia do marketing, uma vez que seus pressupostos se diferenciam dos seus aspectos tradicionais.

Dentre os tipos de problema socialmente relevantes, a TCR tem se dedicado especialmente ao consumo impulsivo, alcoolismo, tabagismo, obesidade, drogas, pobreza, materialismo, alergias de alimentos, vulnerabilidade de grupos, como pessoas com deficiência, analfabetos, negros, idosos e a vulnerabilidade de consumidores de serviços financeiros (ACR, 2015; PETTIGREW et al., 2014). Para estudar estes temas, ela se alicerça em quatro diretrizes, proposta pelo seu precursor Mick et al. (2012): 1) Conhecimento prático: para soluções imediatas dos problemas sociais por meio do consumo, já que os pesquisadores transformadores prometem que a mudança social será realizada; 2) Contribuições de construções teóricas: embora não seja prioridade, clama-se por um designer inovador de pesquisa. Como exemplo, pode-se incluir a TCR nos estudos nos programas de doutorado em Administração, mas em parceria com outras áreas inter e transdisciplinares; 3) Aproximação dos pesquisadores com os agentes da mudança social e; 4) Adoção de estratégias de comunicação alternativas, divulgando para elaboradores de políticas públicas, organizações sociais e mídia.

\section{As Contribuições da CNV à TCR no Contexto da Insegurança Alimentar}

Tendo exposto, agora já é possível traçar um paralelo entre as congruências e contribuições da CNV para a TCR (QUADRO 3).

Quadro 3: Contribuições da CNV à TCR.

\begin{tabular}{|c|c|c|}
\hline $\begin{array}{l}\text { Fase da } \\
\text { pesquisa }\end{array}$ & Pesquisa Transformativa & Comunicação não-violenta \\
\hline $\begin{array}{l}\text { Identificação } \\
\text { do problema }\end{array}$ & $\begin{array}{l}\text { Examina problemas sociais } \\
\text { significativos em sua complexidade; } \\
\text { como obesidade, fome, vulnerabilidade } \\
\text { de pessoas com deficiência, etc. } \\
\text { - Abordagens longitudinais e com } \\
\text { múltiplas perspectivas. }\end{array}$ & $\begin{array}{l}\text { - Examina problemas sociais de consumidores em } \\
\text { situação de vulnerabilidade ainda mais profunda, } \\
\text { como membros de uma guerra atual, grupos de } \\
\text { tribos indígenas, famílias que não se comunicam } \\
\text { há décadas, trabalhadores com agência subjugada } \\
\text { pela estrutura organizacional. } \\
\text { - Abordagem longitudinal, envolvendo paciência, } \\
\text { tempo e disponibilidade de longas viagens, } \\
\text { conforme o contexto. Foco em uma única } \\
\text { perspectiva para identificar o problema: Qual a }\end{array}$ \\
\hline
\end{tabular}




\begin{tabular}{|c|c|c|}
\hline & & $\begin{array}{l}\text { necessidade não é atendida? O autor entende que } \\
\text { focar uma força aumenta as chances de aprofundar } \\
\text { no caso e resolução do problema. }\end{array}$ \\
\hline $\begin{array}{l}\text { Grupo de } \\
\text { pesquisadore } \\
\text { S }\end{array}$ & $\begin{array}{l}\text { - Formado por grandes equipes } \\
\text { multidisciplinares. }\end{array}$ & $\begin{array}{l}\text { - Todos são convidados a praticarem à CNV. } \\
\text { Contudo é preciso ter como princípio individual a } \\
\text { promoção do bem-estar e não o status, poder ou } \\
\text { ganho de dinheiro, que possivelmente, podem não } \\
\text { vir. }\end{array}$ \\
\hline $\begin{array}{l}\text { Definição dos } \\
\text { sujeitos }\end{array}$ & $\begin{array}{l}\text { - Amostragem flexível e criativa, } \\
\text { equilibrando rigor e relevância. }\end{array}$ & $\begin{array}{l}\text { - São selecionados sujeitos que estão em condição } \\
\text { de vulnerabilidade e não possuem a consciência de } \\
\text { si e do outro, o que reflete na negação da sua } \\
\text { responsabilização, num dado contexto. }\end{array}$ \\
\hline $\begin{array}{l}\text { Coleta de } \\
\text { dados }\end{array}$ & $\begin{array}{l}\text { - Adoção de um conjunto amplo de } \\
\text { técnicas, buscando maior inovação nos } \\
\text { métodos utilizados. }\end{array}$ & $\begin{array}{l}\text { - Trabalha apenas com o processo de conversa em } \\
\text { conjunto, com as partes que influenciam a } \\
\text { vulnerabilidade. O autor entende que é importante } \\
\text { as duas ou mais partes se disporem a ouvir o outro } \\
\text { de forma não violenta, para resolver o problema. } \\
\text { É o que a abordagem chama de interação } \\
\text { compassiva. }\end{array}$ \\
\hline $\begin{array}{lr}\text { Processo re } \\
\text { análise dos } \\
\text { dados }\end{array}$ & $\begin{array}{l}\text { - Análise colaborativa entre } \\
\text { pesquisadores e participantes em prol da } \\
\text { comunidade. }\end{array}$ & $\begin{array}{l}\text { - Igualmente, promove uma análise colaborativa, } \\
\text { entre pesquisadores e participantes em prol dos } \\
\text { vulneráveis. Reforçando a dificuldade que os } \\
\text { participantes têm de ouvirem e serem ouvidos, } \\
\text { mas que atingir este estágio é fundamental para } \\
\text { promover a transformação. }\end{array}$ \\
\hline $\begin{array}{l}\text { Tradução da } \\
\text { pesquisa }\end{array}$ & - Aplicação dos resultados & $\begin{array}{l}\text { - Igualmente, busca a aplicação dos resultados. O } \\
\text { pesquisador somente sai do campo quando a } \\
\text { transformação ocorre, o que demanda uma } \\
\text { abordagem longitudinal de anos ou décadas. }\end{array}$ \\
\hline $\begin{array}{l}\text { Disseminaçã } \\
\text { o da Pesquisa }\end{array}$ & $\begin{array}{l}\text { - Divulgar os resultados em ampla gama } \\
\text { de veículos de comunicação utilizados } \\
\text { pelos consumidores. }\end{array}$ & $\begin{array}{l}\text { - Recomenda a utilização por meio de palestras, } \\
\text { vídeos e outros meios alternativos das Artes, } \\
\text { incluindo o teatro ou uso da música. Contudo, o } \\
\text { problema de vulnerabilidade pode ser algo focal, o } \\
\text { que demanda uma disseminação inicial para os } \\
\text { sujeitos atingidos. }\end{array}$ \\
\hline
\end{tabular}

Fonte: Adaptado de MICK et al., 2012; CROCKETT et al., 2013 e ROSENBERG, 2006.

De início, o Quadro 3, aliado ao desenvolvimento deste ensaio, parece mostrar que a TCR e a CNV têm o bemestar social como ponto importante e o fazem por uma visão transformativa. Contudo, ao ler a obra seminal sobre a TCR de Mick et al. (2012), ficam claros os pressupostos do que precisa ser feito em um estudo transformativo, mas não tão claro como metodologicamente seguir este caminho. Neste ponto, a CNV contribui ao indicar que essa transformação deve iniciar de um ato de própria vontade do pesquisado, e não por coação ou julgamentos morais do pesquisador, pois isso poderia levar a resistência, trazendo uma comunicação que bloqueia a transformação (ROSENBERG, 2006).

Nesta linha de raciocínio, a CNV pode ser uma aliança à TCR, ao indicar um caminho discursivo (via comunicação) que o pesquisador inicia seu trabalho tentando compreender quais as necessidades não são atendidas e colocam àquele consumidor na condição de vulnerabilidade. Essa etapa é feita por meio de uma pergunta direta, mas que o pesquisador deverá ter a sensibilidade suficiente para entender o discurso que está por trás daquela Comunicação Violenta, se for o caso, dado que Rosenberg (2006) nos lembra que nossa mente está programada histórica, social e culturalmente para darmos respostas patológicas aos fatos, e não para centrar os esforços em nossas necessidades não atendidas.

Com isso, esse processo dialético é moroso, pois pode demandar uma rodada de conversas de anos ou décadas com o participante ou grupos vulneráveis envolvidos, tentando compreender exatamente como e por qual motivo determinada necessidade não é atendida. Em se tratando dos problemas de má alimentação, Rosenberg (2006) cita o exemplo empírico de duas tribos indígenas que estavam em guerra e com dificuldade de acesso a alimentação, 
por bloqueio de território pelo grupo dominador. Depois de meses de conversa simultaneamente com os dois grupos no mesmo local, o autor conseguiu perceber que o problema estava relacionado com uma necessidade de segurança não atendida. Isso parece óbvio no contexto, mas as duas tribos não percebiam, pois partiam de uma Comunicação Violenta, categorizando cada parte com base em seus julgamentos morais, que não levavam a transformação desejada e reforçava a fome.

Afinal, como comentando, Rosenberg (2006) diz ser difícil retirar um grupo de uma situação vulnerável quando tudo que se vê é uma imagem inimiga a sua frente. Essa morosidade, portanto, demandará do pesquisador tempo, dinheiro, paciência e longas viagens, de acordo com o contexto, como demonstramos no Quadro 3. É o mesmo pressuposto da TCR, já que tanto ela quanto a CNV se dedicam a permanecer em campo com estudos longitudinais de anos ou décadas. O que leva a outra convergência entre CNV e TCR que é a coerência de vida do pesquisador, que deve ter valores pessoais que convergem com a interação compassiva sugerida pela $\mathrm{CNV}$, e não citada nas obras da TCR, mas que possui forte sintonia.

Partindo do exemplo da violência entre as tribos indígenas, pode-se observar outra contribuição da CNV para a TCR. O público vulnerável que a TCR trabalha são consumidores idosos, negros, obesos, com deficiência, crianças, etc. Já a CNV trabalha com esse público e avança, estudando grupos ainda mais a margem, são tribos indígenas historicamente marginalizados, grupo localizados em países com guerras constantes, trabalhadores com agência subjugada nas estruturas organizacionais, membros de famílias que não conversam entre si durante toda uma vida, dentre outros. A expressão do término da vulnerabilidade destes grupos, segundo Rosenberg (2006), só finaliza com a morte total de um deles ou do seu líder, em alguns casos, e, daí a importância de instituir uma CNV antes de chegar a este estágio. Essas pessoas, embora também assumam o papel social de trabalhadores, familiares, soldados de uma guerra, dentre outros, são também, antes disto, consumidores, gostem eles ou não (MICK et al., 2012). Assim, a vulnerabilidade no trabalho ou na vida tem reflexos no seu papel enquanto consumidores e, numa visão do Macromarketing, essa aliança entre CNV e TCR parece ser interessante para o campo da Administração e dos estudiosos do consumo, já que incorpora o Marketing à Sociedade e aos seus problemas sociais relevantes.

Em outro ponto, TCR e CNV acreditam ser possível criar um mundo melhor, na visão das pessoas envolvidas. Se pensarmos no conceito de Tecnologia exposto no início do trabalho, as duas abordagens são convergentes com a ideia da Teoria Crítica da Tecnologia. Contudo, a CNV parece focar muito mais na agência do indivíduo (mais humanamente controlada), afirmando que ele possui capacidade de atingir uma consciência de si e do outro, e transformar-se independente da estrutura, a partir do momento em que o participante também encare a verdade e visualize sua responsabilização no contexto. Já a TCR, parece equilibrar um pouco mais o debate entre estrutura e agência. Se pensarmos, por exemplo, que ela acredita que a transformação também ocorre quando criada uma estrutura de políticas públicas (legislações, por exemplo), que busquem garantir os direitos e reduzir a vulnerabilidade antes observada. Ou seja, a pessoa individualmente ou em grupo não possuem tamanha agência prevista pela $\mathrm{CNV}$, se não houver uma estrutura que caminhe e evolua paralelamente ou em passos ainda maiores que sua agência, numa visão inicial.

Finalmente, a última contribuição que vemos da CNV à TCR, está no fato dela afirmar que ensinar o outro para mudar não produz transformação, mas sim aumentam as chances de resistência (ROSENBERG, 2006). O autor coloca que a transformação ocorre quando o participante dá mais foco ao desenvolvimento da empatia, transformando-se por um ato de própria vontade, do que via simpatia, isto é, mudando para agradar o outro. Essa visão transformativa ajuda a compreender a transformação que a TCR propõe e ajuda o pesquisador a trilhar o caminho para alcançá-la.

Tendo em vista toda a discussão travada anteriormente, é possível, no contexto da insegurança alimentar, vislumbrar que a $\mathrm{CNV}$ e a TCR podem ser úteis em situações de insegurança alimentar em grupos vulneráveis em diversos pontos. Em primeiro lugar, é essencial destacar que ambas (CNV e TCR) são focadas em grupos vulneráveis. Em segundo lugar, a questão da insegurança alimentar tem total aderência aos projetos da TCR, uma vez que compreende um movimento de pesquisas que destina esforços na melhoria da qualidade de vida de indivíduos vulneráveis.

Em terceiro lugar, e de forma mais contundente, ao se analisar o quadro 3, percebe-se que em todas as fases apresentadas no tocante a uma pesquisa envolvendo a TCR, projetos atinentes à temática da insegurança alimentar em suas diversas dimensões. Com relação à fase de identificação do problema, deve-se ressaltar que os pesquisadores não partem para o campo com o problema já definido. Pelo contrário, são os indivíduos pesquisados, a partir de suas vivências e perspectivas que informarão quais são seus problemas e demandas. Quando se pensa em insegurança alimentar isso parece fazer todo o sentido, pois é essencial que as pessoas sejam ouvidas e seus hábitos e práticas culturais sejam levadas em conta. O grupo de pesquisadores deve ser multidisciplinar, o que também se adequa a situações de insegurança alimentar, visto que é essencial a participação de profissionais de diferentes campos do conhecimento como nutricionistas, médicos, psicólogos, assistentes sociais, sociólogos, entre outros. A fase de coleta de dados é especialmente importante para projetos envolvendo situações de 
insegurança alimentar em grupos vulneráveis, uma vez que, como se adota um conjunto amplo de técnicas é interessante que se foque em processos de conversa em conjunto, o que os autores denominam de interação compassiva. O processo de análise dos dados não é o ponto final como em uma pesquisa tradicional. É essencial que a analise de dados subsidie as outras duas fases da pesquisa transformativa que são a sua tradução e disseminação. Cabe salientar que a tradução da pesquisa deve focar na transformação dos sujeitos. Para isso, as devolutivas são ações de suma importância para os projetos de insegurança alimentar, tendo em vista que deve promover mudanças de hábitos e comportamentos de consumo de alimentos.

Nesse ponto, torna-se adequado caminhar a discussão para as considerações finais, tema da próxima seção.

\section{Contribuições do artigo: Articulações entre a TCR e a CNV}

Esse trabalho teve como objetivo descrever as contribuições da Tecnologia Social denominada Comunicação NãoViolenta para o desenvolvimento e fortalecimento da TCR, o que pode refletir na tentativa de minimizar problemas oriundos da insegurança alimentar entre grupos vulneráveis. Diante disso, a principal contribuição está na forma em que a abordagem transformativa é sugerida pela CNV. Afinal, a transformação não se faz por coerção, manipulação, culpa, convencimento, diagnósticos e julgamentos morais. O que se ganha ao aliar a CNV com a TCR é que a pessoa ao adquirir a consciência de si e do outro, disponha a transformar-se, direcionando seu próprio pensamento às suas necessidades não atendidas, sendo o papel do pesquisador, ser apenas um mediador para ajudar o outro a encará-las.

Contudo, é difícil chegar a essa fase quando se vê o outro como inimigo. Ao ultrapassar este estágio por meio de uma Comunicação Não-Violenta pode-se, por exemplo, reduzir conflitos como a fome, uma vez que a comida é abundante, mas não acessível a todos os consumidores em função das disputas de território, legitimadas pelo discurso de poder e supremacia. Essa proposta possui um potencial colaborativo para a TCR, ao trabalhar por meio da emancipação do participante da pesquisa através da empatia.

A CNV, contudo, traz contribuições complementares, que discutimos ao longo do trabalho, quer sejam: a) a interação compassiva e seu poder para contribuir com o bem-estar do indivíduo; b) a comunicação violenta, enquanto cultura legitimada de dominação do discurso que justifica o uso da violência e reduz o potencial transformativo; c) contribui para a delimitação do conceito de transformação, reduzindo as críticas que lhe são caras, pois tanto a CNV quanto a TCR não objetivam educar a pessoa para transformá-la, antes, se comprometem a despertá-la a fim de que ela transforme-se.

Tal como discutido anteriormente, a articulação entre a TCR e a CNV parece trazer contribuições interessante para situações de insegurança alimentar entre indivíduos vulneráveis.

\section{Considerações Finais}

Nessa parte final, destacaremos as limitações e sugestões para novos trabalhos. Como limitações, a proposição apenas teórica nos restringe a um olhar, que empiricamente talvez robusteçam novas contribuições ou nos façam retroceder em algumas afirmações. Além disto, essa é a primeira proposição de articulação entre uma Tecnologia Social denominada CNV para o campo da TCR, o que restringe em reflexões ainda mais profundas, haja vista que nem empiricamente quanto teoricamente alguém se propôs em aliá-las. Levando em conta a característica mais importante da TCR que é a importância de se estar no campo e construir a pesquisa continuamente ao longo de todo o processo, fica fácil perceber que outras questões podem (e vão) surgir quando se "sai do gabinete" e se "suja de campo" na interação com os pesquisados.

Para novos trabalhos, pode-se aprofundar na discussão inicial ilustrada timidamente ao longo do artigo sobre CNV, TCR e Agência e Estrutura. Afinal, parece que a CNV contribui à TCR, pelo menos numa análise inicial, empoderando mais esse sujeito e tornando-o ainda mais autônomo do que tem previsto a abordagem transformativa do consumidor. Isso porquê a CNV acredita ser possível formar o mundo, a partir da consciência individual e da responsabilização da pessoa, o que é equivalente a abordagem da Teoria Crítica da Tecnologia. Ao passo que a TCR descreve também a necessidade de as políticas públicas avançarem, por exemplo, o que remete a um foco maior na estrutura. Claro que se trata de um pressuposto que precisa ser melhor compreendido empiricamente, sendo, portanto, uma agenda e um convite à academia.

Ao mesmo tempo e aliado novamente a discussão entre Agência e Estrutura, outra agenda pode ser colocada, equivalente a proposição de uma abordagem da Transformative Consumer Research em Movimento, que poderia ser denominada TCR-M, não proposta nacional e nem internacionalmente. Nesta, poderia se estudar qual o movimento (no sentido de fluxo, como uma analogia a um fluxo de um rio), que parte a Transformação prevista na TCR: Essa transformação se movimenta mais da agência para estrutura, ou mais da estrutura para agência? É 
claro, que não é algo polarizado, pois o poder está distribuído, mas a ideia aqui é entender de onde a transformação se inicia e para quais direções ela parte num dado contexto: se alimentando, retroalimentando e talvez retrocedendo, o que retira ou reforça a vulnerabilidade do consumidor.

Essa proposta parte após a leitura da obra de Mick et al. (2012), em que muito se estuda sobre como retirar o consumidor de uma condição vulnerável e, os estudos posteriores, tem afirmado sucesso nessa tentativa. Mas, não encontramos estudos nacionais e internacionais que mostrem quais os movimentos (no mesmo sentido de fluxo) que reforçam a vulnerabilidade do consumidor, ainda que a academia tente alianças para promover uma transformação. Inclusive, não encontramos estudos que revelem a impossibilidade transformativa do consumidor, em um contexto, em virtude de um dado movimento, partindo da TCR: esse movimento inicia mais da presença ou ausência de alianças e vai em direção ao consumidor, ou se inicia do desejo do consumidor ou do grupo de pesquisadores e vai em direção as alianças? Muitos movimentos podem surgir, a partir desta proposição.

Ao compreender histórico, social e culturalmente esse fluxo do movimento transformativo (mapeando-o teoricamente e empiricamente), talvez uma única pesquisa não chegue a uma mudança, mas esse insucesso de um estudo pode levar a outros estudos longitudinais (como prevê a CNV e a TCR), para que demais acadêmicos consigam perceber qual o movimento bloqueou a transformação em um contexto e procure novas soluções transformativas. O que parece ser bastante possível, se chegarmos ao ponto de compreender a abordagem Transformativa do Consumidor - em Movimento, proposta num paradigma Interpretativista ou, talvez, avançando para o Humanismo Radical, e bastante adequada a formação do Administrador, como gestor também capaz de mapear o movimento do contexto do contexto. Lembrando que, nossa proposta da TCR-M para agendas futuras está no "fluxo da transformação" do consumidor, e não isoladamente no indivíduo ou grupo. Finalmente, essa discussão parece ser benvinda aliando TCR, CNV e a discussão de agência e estrutura ao Marketing e Sociedade

\section{Referências}

ABRAMIDES, M. B. C.; CABRAL, M. S. R. Regime de acumulação flexível e saúde do trabalhador. São Paulo em Perspectiva, São Paulo, v. 17, n. 1, p. 3-10, Mar. 2003.

ACR - ASSOCIATION FOR CONSUMER RESEARCH. Transformative Consumer Research. 2015. Disponível em: $<$ http://www.acrwebsite.org/web/tcr/transformative-consumer-research.aspx $>$. Acesso em: 10 jun. 2016.

ALMEIDA, L. M. M. C. et alli. Políticas públicas, redes de segurança alimentar e agricultura familiar: elementos para construção de indicadores de eficácia. Estudos Sociedade e Agricultura, vol. 14, no. 2, p. 205-235, 2006.

BARBIERI, J. C. Sistemas Tecnológicos Alternativos. Revista de Administração de Empresas, v. 29, n. 1, p. 3545, Jan.-Mar., 1989.

BARRETTO, S. F. A.; PIAZZALUNGA, R. Tecnologias sociais. Ciência e Cultura, v. 64, n. 4, p. 4-5, 2012. BUAINAIN, A. M.; GARCIA, J. R.; VIEIRA, P. A. O desafio alimentar no século XXI. Estudos Sociedade e Agricultura, vol. 24, n. 2, p. 497-522, 2016.

CNVC. Center for nonviolent communication: na international organization, 2015. Disponível em $<$ www.cnvc.org $>$ Acesso em 04 de Jul. 2016.

CORREA, A. M. S. Insegurança alimentar medida a partir da percepção das pessoas. Estudos Avançados 21, 60, p. 143-154, 2007.

CROCKETT, D.; et al.. Conceptualizing a transformative research agenda. Journal of Business Research, v. 66, n. 8, p. 1171-1178, 2013.

DAGNINO, R. P. Neutralidade da ciência e determinismo tecnológico: um debate sobre a tecnociência. Campinas: Unicamp, 2008.

Introdução. In: DAGNINO, R. Tecnologia social: ferramenta para construir outra sociedade. Campinas, SP: Unicamp, 2009. 5-16 p.

A Tecnologia Social e seus Desafios. In: Tecnologia Social: Ferramenta para Construir outra Sociedade. 2. ed. Campinas, SP : Komedi, 2010.

DAVIS, B.; OZANNE, J. L.; HILL, R. P. The Transformative Consumer Research Movement. Journal of Public Policy \& Marketing, 35, n. 2, 2016. 159-169.

DAVIS, B.; PECHMANN, C. Introduction to the Special Issue on transformative consumer research: Developing theory to mobilize efforts that improve consumer and societal well-being. Journal of Business Research, 66, n. 8, 2013. 1168-1170.

FEENBERG, Andrew. Teoria Crítica da Tecnologia. Texto original "Critical theory of technology". Tradução da Equipe de Tradutores do Colóquio Internacional "Teoria Crítica e Educação". Unimep, Ufscar, 2004. 
. Teoria Crítica da Tecnologia: um panorama. Texto originalmente publicado em TailorMade BioTechnologies, v.1, n.1, abr/maio, 2005.

Cinco Paradoxos da Tecnologia e da Política de Desenvolvimento. In: OTERLOO, A. et. al. Tecnologias Sociais: caminhos para a sustentabilidade. Brasília: s.n., 2009.

HEATH, T. P.; CHATZIDAKIS. The transformative potential of marketing from the consumers' point of view. Journal of Consumer Behavior, 11, n. 4, 2012. 283-291.

HERRERA, A.. La generación de tecnologías em las zonas rurales. In: Tecnologia Social: ferramenta para construir outra sociedade. In: DAGNINO, R. (org.). 2. ed. Campinas, SP: Komedi, 2010.

LASSANCE JR., A. E. et al. Tecnologia Social: Uma estratégia para o desenvolvimento. Rio de Janeiro: Fundação Banco do Brasil, 2004.

MARI, C. Book Review: David Glen Mick, Simone Pettigrew, Cornelia Pechmann, and Julie L. Ozanne (eds.): Transformative Consumer Research for Personal and Collective Well-Being. J Consum Policy, 34, 2011. 475-480.

MERTENS, D. Transformative considerations: inclusion and social justice. American Journal of Evaluation, v. 28, n. 1, p. 86-90, 2007.

MERTENS, D. M. Transformative Paradigm. Journal of Mixed Methods Research, 1, n. 3, 2007a, $212-225$.

MICK, D. G.; PETTIGREW, C.; PECHMANN, J.; L. OZANNE (eds.), Transformative Consumer Research for Personal and Collective Well-Being. New York: Routledge, 2012.

NABEC, L. Améliorer les comportements alimentaires avec l'étiquetage nutritionnel : vers un agenda de recherche au service du Bien-être des consommateurs. Recherche et Applications en Marketing, v. 32, n. 2, p. 76-104, 2017.

NEDER, R. T. Direitos de propriedade comum das Tecnologias Sociais como ambiente de inovação social. Brasília: UnB, 2009.

OTTERLO, A. et al. Tecnologias sociais: Caminhos para a sustentabilidade. Brasília: Rede de Tecnologia Social, 2009.

PARKER, M. Mick, D, Pettigrew, S, Pechmann, C and Ozanne, J (eds) (2012), Transformative Consumer Research for Personal and Collective Well-Being. Journal of Consumer Culture, 14, n. 1, 2014.

PEREIRA, R. A.; SANTOS, L. M. P. Prefácio: A dimensão da insegurança alimentar. Revista de Nutrição, 21(Suplemento), p. 7-13, 2008.

PETTIGREW, S. et al. The experience of risk in families: conceptualisations and implications for transformative consumer research. Journal of Marketing Management, 30, n. 17-18, 2014. 1772-1779.

RODRIGUES, I.; BARBIERI, J. C. A emergência da tecnologia social: revisitando o movimento da tecnologia apropriada como estratégia de desenvolvimento sustentável. Revista de Administração Pública, v. 42, n. 6, p. 1069-1094, 2008.

ROSENBERG, M. B. Comunicação não-violenta: técnicas para aprimorar relacionais e profissões. São Paulo, Ágora, 2006.

SCHUMACHER, E. F.. O trabalho do grupo de desenvolvimento de tecnologia intermediária. Revista de Administração de Empresas, v. 14, n. 3, p. 133-144, 1974.

TADAJEWSKI, M. et al. The discourses of marketing and development: towards 'critical transformative marketing. Journal of Marketing Management, 30, n. 17-18, 2014. 1728-1771. 